\title{
La lectura de la joya en el cuerpo de la mujer: La ajorca de oro de Bécquer y de Ilangô Adigal '
}

\author{
Reading Jewelry in the Woman's Body: \\ La ajorca de oro by Bécquer and llangô Adigal \\ MARÍA VICTORIA GALLOSO CAMACHO \\ Universidad de Huelva \\ España \\ vgalloso@uhu.es
}

(Recibido: 05-08-202O; aceptado: II-II-2O2O)

Resumen. En este artículo se expone uno de los enfoques de la teoría del discurso multimodal (O'Halloran, 20I4) a partir del análisis de los ornamentos en el cuerpo de la mujer en dos obras literarias con idéntico título y pertenecientes a dos momentos históricos muy distanciados: una, escrita por el príncipe llangó Adigal hacia el siglo II de nuestra era, ambientada en el deslumbrante mundo de la India del Sur; otra, por Gustavo Adolfo Bécquer en I86I, y que relata también una historia de amor de una pareja de jóvenes en la ciudad de Toledo. Se estudia la función de estas joyas y su diseño visual en Las ajorcas de oro como un análisis semiótico comparativo de muestras ornamentales.

Palabras clave: ornamento; literatura universal, multimodalidad, semiótica, análisis del discurso.
Abstract. This article presents one of the approaches of multimodal discourse analysis (O'Halloran, 20I4), on the basis of the presence of jewelry adorning the female body in two literary works sharing the same title, although belonging to two very different historical contexts. The first work was written by the Jain Prince llango Adigal towards the second century $A D$, and it is inspired by the splendid surroundings of Southern India. The second work was written by the Spanish poet Gustavo Adolfo Bécquer in I86I, and it tells the love story of two young people in the city of Toledo. The function of the jewels and their visual design in Las ajorcas de oro are studied as a comparative semiotic analysis of ornamental samples.

Keywords: ornament; world literature; multimodality; semiotics; discourse analysis.

\footnotetext{
I Para citar este artículo: Galloso Camacho, Ma Victoria (2O2I). La lectura de la joya en el cuerpo de la mujer: La ajorca de oro de Béquer y de Ilangô Adigal. Alabe 23 . [www.revistaalabe.com] DOI: IO.I5645/Alabe2O2I.23.I
} 


\section{Introducción}

Este artículo se propone analizar una parte del valor de la joya en la literatura, explorar la manera en que un objeto diseñado para adornar el cuerpo de la mujer, incluso el cuerpo del hombre, opera en distintos textos literarios.

Durante los últimos años, el interés académico por la moda, la cultura material y la literatura ha aumentado de manera significativa. Ya en la Edad Media, la vestimenta se consideraba una parte fundamental de la expresión de identidad. La ropa y la moda han sido utilizadas a lo largo de la historia para simbolizar el estatus social, la ocupación, o el género de las personas. Y, aunque la joya es un lenguaje visible con significados que cambian con el paso del tiempo y en diferentes contextos culturales, en este trabajo veremos cómo dicho significado no ha variado

Hasta día de hoy, el análisis de las joyas en la lectura de las obras literarias ha recibido poca atención. Sin embargo, en los últimos años se ha ampliado y mejorado el aprendizaje de la lectura del detalle, la multimodalidad: lecturas en torno a la cultura material, la moda y la literatura. Para ello, explicaremos la teoría del discurso multimodal (O’Halloran, 20I4) a partir del análisis de los ornamentos en el cuerpo de la mujer en dos obras literarias con idéntico título y pertenecientes a dos momentos históricos muy distanciados. Se estudia la función de estas joyas y su diseño visual en las ajorcas de oro como un análisis semiótico comparativo de muestras ornamentales. Este artículo se propone, además, extender este debate hacia otras áreas de la literatura y considerar el rol cambiante de las joyas en el mundo literario. En los personajes femeninos, el énfasis en la joyería tiene una fuerte carga cultural. Históricamente, llevar joyas caras se consideró una manera de garantizar la belleza de las mujeres o su modo de atraer al hombre para alcanzar una buena posición social.

Los textos seleccionados corresponden a dos obras literarias de épocas muy lejanas en el tiempo y que, sin embargo, además de coincidir curiosamente en el título, abordan los debates sobre la cultura de las joyas y los adornos en la literatura desde la perspectiva de los estudios de género y la crítica de la cultura que se deriva de estos últimos, prestando especial atención a la evolución histórica de dicha representación. En ambas obras, una ajorca de oro es el elemento que establece el vínculo entre hombre y mujer. Es de esta forma como se alcanza a entrar en la historia social y tomar en consideración la relación entre el amor, el matrimonio, la traición y la cultura material. El objetivo es animar a aprender los textos a partir del análisis de la representación de las joyas y los adornos corporales en el cuerpo de la mujer y sus consecuencias históricas, sociales, culturales y literarias. 


\section{Estado de la cuestión}

En los últimos años, el concepto tradicional de texto ha ido sufriendo diversas modificaciones, al tiempo que las necesidades de comunicación han ido cambiando, de modo que en la actualidad un texto no se compone solo de letras, sino que puede ir acompañado de imágenes, gráficos, vectores, colores, cuadros, sonidos, tonos, etc. Y con este cambio, han ido apareciendo diferentes estudios sobre cómo se reciben todos los mensajes dados por cada uno de los componentes de la multimodalidad.

La multimodalidad es un fenómeno social que apunta a los diversos recursos semióticos que constituyen un mismo proceso comunicativo para transmitir un mismo mensaje o, dicho de otro modo, "cualquier texto que significa a través de la interacción de más de un recurso, puede ser definido como un texto multimodal independiente del medio - interacción cara a cara, impreso o electrónico - en el cual se distribuye" (Manghi, 2OI3: 243). En esta visión del análisis multimodal, incluso el soporte, que cada vez es más variado (libros ilustrados, páginas web, periódicos, entre otros), ofrece información importante al texto, porque "todo es lenguaje porque todo comunica".

Es en este contexto donde se enmarca este trabajo, pues nuestro objetivo es analizar las joyas como imagen en el cuerpo de la mujer en la literatura, de forma que obtengamos una visión multidisplicinar que considere tanto la perspectiva lingüística como la perspectiva semiótica, sobre todo para comprobar qué importancia tiene la imagen como contribución significativa para alcanzar los objetivos de aprendizaje. Para ello, comenzaremos explicando el novedoso concepto de la multimodalidad y los distintos análisis de discurso multimodal (en adelante ADM) y sus aplicaciones para, posteriormente, mostrar cómo funcionan en las obras seleccionadas.

Este análisis parte del modelo de Kress y van Leeuwen (2006) y O’Toole (2OIO), quienes proporcionaron los fundamentos de la investigación multimodal en las décadas de r980 y I990 siguiendo la teoría del lenguaje como semiótica social de Halliday (2004). Para dar forma al potencial de significado de las palabras, los sonidos y las imágenes como conjuntos de sistemas interrelacionados y sus estructuras, Kress y van Leeuwen (2006) exploraron las imágenes y el diseño visual y O’Toole (2OIO) aplicó el modelo sistémico funcional de Halliday al análisis semiótico de muestras de arte, pintura, escultura y arquitectura. En esta multimodalidad, cada recurso semiótico es capaz de ofrecer una significación tan concreta que no puede compararse con otros recursos. Esta potencial significación se debe tanto al material usado para la presentación del recurso como a los usos sociales establecidos para este medio o mecanismo semiótico que son acordes tanto a las necesidades establecidas por cada comunidad como con sus posibilidades futuras de uso (Kress y van Leeuwen, 2006; Manghi, 20I3). Dicho de otro modo, un mecanismo semiótico, como, por ejemplo, una joya o un adorno, contiene una información mucho más compleja y concreta que su verbalización o cualquier otra representación posible, ya que se enmarca en un contexto social en el que este recurso es capaz de ofrecer gran cantidad de información en un marco de referentes codificados compartidos, lo que dificulta su sustitución por otro recurso semiótico capaz de dar cuenta de todas las significaciones. 
La mayoría de los estudios de esta vía investigativa centran su trabajo en ofrecer diferentes propuestas metodológicas para el análisis de estos mecanismos y para conseguir dar respuesta a lo que se ha venido a llamar el análisis del discurso multimodal. Como cita Cárcamo (20I8), el ADM se está abordando en la actualidad desde variadas miradas, de modo que existen autores como Parodi (2OIO) que se interesan en el análisis de corpus de comunidades discursivas específicas intentado identificar qué mecanismos multimodales usan mientras que otros, como Kress y Van Leeuwen (2006) u O’Halloran y Lim (20I4), estudian el sentido y efecto de la elección de dichos mecanismos. Sin embargo, el ADM es un campo novedoso abierto a continuas nuevas líneas de investigación.

La importancia de la comunicación a través de la imagen es cada vez más reconocida en la actualidad y es importante la recuperación del concepto de iconosfera para reseñar que, aunque el mundo de la imagen ha conquistado la vida del hombre moderno, la mirada que este lanza suele ser pasiva, ausente de una mirada crítica que somete posicionamientos libres y, por tanto, divergentes ante el mundo. Por ello, es necesaria una formación específica que ayude a leer la imagen de forma crítica, evitando manipulaciones: la imagen domina nuestro entorno, determina nuestro desenvolvimiento diario y no lo hace inocentemente. Nos llega cargada de intenciones. El desarrollo de la competencia lectora como forma de alfabetización de las sociedades contemporáneas debe ser, por tanto, un objetivo del educador; así ha sido expuesto en las investigaciones de Prensky (2OOI) y, más recientemente, en los estudios de Hug (2OI3).

Todo es lenguaje. Si nos detenemos a estudiar el sentido del adorno femenino en la literatura, debemos realizarlo desde la semiótica. Como toda imagen, el adorno femenino puede ser portado físicamente (caso de la ajorca de oro y otras joyas femeninas de la obra hindú) y son entonces una suerte de alter-ego de la persona con que denotar ideologías, creencias, actitudes... Y puede ser, incluso, más que un trasunto de la mujer que las asume, puede tratarse de una imagen que la suplante en su ausencia o que la ponga en relación con otras cuando la presencia está fuera de ella (caso de la ajorca de oro becqueriana).

Rivera (2006) se ha detenido a estudiar el sentido del adorno femenino en la literatura. Según dicha autora, la comprensión de la polémica sobre por qué o para quién se han adornado las mujeres se ve dificultada si no se entiende que las mujeres han vivido en una sociedad patriarcal que tiene como una de sus instituciones básicas la heterosexualidad obligatoria. La condena por parte del discurso patriarcal del adorno de las mujeres o bien, al contrario, conformar el adorno como algo que las mujeres hacen para atraer a los hombres, llevándolo muchas veces a su exageración y a la manipulación, se inscribiría dentro de estos parámetros que, a través de la institución de la heterosexualidad obligatoria, reprimen actitudes o acciones y manipulan su significado último. De esta manera, la práctica del adorno del cuerpo femenino formaría en su sentido primigenio parte del orden simbólico.

En este artículo se analizan recursos semióticos en referencia a lenguajes como las imágenes y la arquitectura decorativa femenina, que se integran en forma transversal 
en modalidades sensoriales (por ejemplo, visual y quinésica) tanto en los textos literarios como en el medio natural, en nuestro caso el cuerpo de la mujer. "Las relaciones "intersemióticas' (o inter-modales) que surgen a partir de la interacción de las opciones semióticas, conocidas como intersemiosis, constituyen un área central de los estudios multimodales" (Jewitt, 2009). Las investigaciones sociolingüísticas actuales deben abordar una cuestión ciertamente amplia y heterogénea -resbalosa, en cierto modo- que es, de hecho, insoslayable. Este estudio responde a esa necesidad. Se trata de una tarea ardua, un proceso abierto cuya construcción en marcha supone la suma de sinergias y al que, desde el presente estudio, se pretende contribuir enfocando la cuestión en un aspecto absolutamente concreto. Por ello, se aborda el análisis de un corpus perfectamente limitado: el aderezo de la mujer en estas dos obras literarias y su valor comunicativo.

Nuestra exposición no pretende sentar cátedra, sino más bien reflexionar sobre un tema que forma parte de nuestra vida. Las joyas y los ornamentos de la mujer han sido señas de identidad de culturas, escaparates de sus portadoras, figuras desde los que comunicamos en silencio quiénes somos o por qué lo somos. Donde hay una joya hay una información; leer en los individuos que las llevan es algo a lo que, los que las portan, no pueden negarse. La sistematización genérica determinadas joyas sobrevivirán a lo largo de los siglos en el sentido de la idealización de la mujer, como sucede en los dos textos analizados.

\section{La ajorca de oro de Bécquer}

En la literatura, es en la obra de Gustavo Adolfo Bécquer (I836-I870) donde se fragua el prototipo, o mejor, los distintos arquetipos de la mujer romántica: etérea, intangible, unas, y otras antecediendo a lo que en la narrativa europea de finales de siglo XIX sería la femme fatal. En sus leyendas, basadas en la tradición, pero elaboradas y recreadas con una poética singular, surgen una serie de tipos femeninos que resultan paradigmáticos a la hora de construir una continuidad en lo referente al ideal femenino. El escritor sevillano sabe profundizar en determinados caracteres femeninos, aunque son pocos los ejemplos en los que menciona la indumentaria de la mujer para dicho fin. Uno de ellos es el que tiene lugar en el cuento La ajorca de oro, cuya protagonista, María, mujer de fatídica belleza, arrastra a su enamorado hasta la locura: pues se ha encaprichado de una presea que luce la Virgen del Sagrario y le induce a robarla: “...mis ojos se fijaron desde luego en la imagen; digo mal, en la imagen no: se fijaron en un objeto que hasta entonces no había visto, un objeto que, sin poder explicármelo, llamaba sobre sí toda mi atención... No te rías... aquel objeto era la ajorca de oro que tiene la Madre de Dios en uno de los brazos en que descansa su divino Hijo...” (p. I98), y continúa “...Yo aparté la vista y torné a rezar... ¡Imposible! Mis ojos se volvían involuntariamente al mismo punto. Las luces del altar, reflejándose en las mil facetas de sus diamantes, se reproducían de una manera prodigiosa. Millones de chispas de luz rojas y azules, verdes y amarillas, volteaban 
alrededor de las piedras como un torbellino de átomos de fuego, como una vertiginosa ronda de esos espíritus de llamas que fascinan con su brillo y su increíble inquietud...” (p. I98).

En esta narración de Bécquer se comienza por una descripción ambigua del amor entre un hombre y una mujer: Pedro Alfonso de Orellana y María de Antúnez. Ella es hermosamente diabólica, caprichosa y extravagante; él es supersticioso, valiente y la ama con el ardor de quien expía una culpa. De esta manera, nos presenta Bécquer a los protagonistas del cuento La ajorca de oro. Ya desde las primeras palabras, el autor nos introduce en un ambiente lleno de remordimientos y misterio, cuya herramienta de acción es una joya, un adorno para una mujer ciega por su posesión. Ella le cuenta cómo ha tenido un sueño en el que ve y le explica “¡Cómo brilla! Parece un círculo de estrellas arrancadas del cielo de una noche de verano" (p. I98).

Se presenta en esta introducción un amor basado en la necesidad y las culpas, una pasión enfermiza. Lo fatídico es presentido por el lector desde el comienzo: "Él la amaba; la amaba con ese amor que no conoce freno ni límites; la amaba con ese amor en que se busca un goce y sólo se encuentran martirios; amor que se asemeja a la felicidad, y que, no obstante, parece infundir el cielo para la expiación de una culpa” (p. I96).

En este ambiente de desdicha e inquietud, el autor se permite la concesión de utilizar el término maravilloso para referirse a la historia que nos narrará. Esta referencia ambigua a lo bello y admirable, tanto como a lo extraordinario y sobrenatural, queda ensordecida por el apabullante y demencial desenlace. Bécquer, al final del apartado, promete además relatarnos la historia con la certeza e imparcialidad de un cronista, y, sin embargo, recibimos de su prosa una despiadada traición en las páginas sucesivas, donde, con absoluta subjetividad, nos sumerge en una historia terriblemente perturbadora y delirante.

María desea poseer una joya de la catedral de Toledo: la ajorca, el brazalete de oro de la Virgen del Sagrario, Patrona de la ciudad. Pedro la encuentra llorando y, al preguntar con insistencia, logra que ella le cuente su herético delirio. El apasionamiento de él y el orgulloso capricho de ella nos inspiran la sospecha de que no actuarán como prometen hacerlo.

En esta obra, la multimodalidad se presenta en el recurso semiótico capaz de ofrecer una significación tan concreta que no puede compararse con otros recursos: la ajorca de oro. Como ya se ha indicado, esta potencial significación se debe tanto al material usado para la presentación del recurso como a los usos sociales establecidos para este medio o mecanismo semiótico que son acordes tanto a las necesidades establecidas por cada comunidad como con sus posibilidades futuras de uso, en distintos momentos históricos, en este caso el valor que la mujer le da a una joya “virginal”, elemento semiótico fruto de belleza femenina y locura masculina. 


\section{La ajorca de oro de Adigal}

La ajorca, del árabe hispánico aśśúrka, y este del árabe clásico śuruk, plural de śirāk: 'correa', es una pulsera o brazalete, de oro, plata, cobre u otros metales -y frecuentemente decorada con esmaltes, pedrería, filigranas y otras labores- que se ponen las mujeres como adorno en los tobillos, muñecas y brazos... No se trata desde luego una invención contemporánea, dado que han llegado hasta nosotros ajorcas nada menos que del Neolítico. Culturas ancestrales como los egipcios ya se adornaban con esta joya de forma cilíndrica con incrustaciones de piedras preciosas y emblemas propios de su imperio. Asimismo, los fenicios, griegos y romanos, se engalanaban con ajorcas que terminaban en cabezas de animales o con forma de serpiente. El Imperio bizantino, por su parte, a través de sus mosaicos, muestra que también fue usado este abalorio, especialmente por las clases altas; sin embargo, lo cierto es que hay escasos restos de dichos complementos en la Edad Media. Ya en el siglo XV sí que se tiene constancia de un uso continuado hasta la Edad Modernay, en la actualidad, la ajorca es un artículo en pleno auge, con miríadas de deslumbrantes diseños, materiales y posibles combinaciones.

De hecho, este mismo recurso semiótico es básico en la obra del Príncipe Ilangô Adigal, escrita hacia el siglo II de nuestra era. Ambientada en el mundo deslumbrante de la India del Sur, esta novela de amores y venganzas es una de las obras maestras de la literatura de la India clásica. La ajorca de oro es una de las principales obras poéticas en tamil, lengua de gran antigüedad hablada en el sur de la India.

Como en la obra de Bécquer, narra los amores del joven Kôvalan con la cortesana Mâdhavi, su posterior vuelta con su esposa Kánnaki, el largo viaje que hacen juntos a otra ciudad y la venganza de Kánnaki cuando aquel es asesinado. Con esta novela, el lector tiene entre sus manos una muestra magnífica de una literatura riquísima y prácticamente desconocida entre nosotros. Mujeres caprichosas, historias de pasión y traiciones que han brotado desde el encanto de la moda en cada momento, de las joyas y los adornos.

En estas dos obras hay ejemplos claros a partir de los cuales analizar la importancia del valor simbólico de la imagen como representación del individuo y de la sociedad y cómo esta se convierte en representación social de distintas épocas. En ambas, se aborda un tema muy actual que es la comunicación a través de la imagen y la función social de la misma. Todos los objetos cotidianos tienen una representación social, creada por los sujetos a partir de su experiencia con el objeto mismo. Es decir, un objeto que está mediado por una figura se convierte en representación. Por lo tanto, la representación está íntimamente relacionada con el referente del objeto. Dichos objetos, dentro de un contexto cultural, hacen referencia a un tipo de conocimiento que se relaciona con lo que los sujetos piensan. Estamos hablando de un conocimiento social porque está socialmente elaborado y ambos autores, con la sobresaliente distancia temporal, han coincidido en objetivos. El conocimiento social explícito en cada momento, a través de este adorno femenino, incluye contenidos cognitivos, afectivos y simbólicos que presentan estereotipos, creencias, valores y normas que han regido la vida social de las mujeres a las que pertenecía una misma joya. 
Las representaciones sociales en un sentido básico, siguiendo a Zabalgoitia (2OII), son resultado de actos cognitivos por medio de los cuales se reproducen signos y símbolos que se instauran en una supuesta realidad. En el caso de este artículo, se trata de la realidad construida en un texto literario de carácter multimodal, cuya referencia semiótica es el adorno en el cuerpo de la mujer, en donde los receptores se adhieren a los mensajes a través de las formas de configuración identitaria. Las representaciones sociales de estas obras están cargadas de ideologías, de contextos socio-históricos y culturales: la lectura de estas dos obras provoca imágenes que producen las protagonistas de las mismas a través de las cuales los lectores creamos nuestras propias visiones de ambos mundos y, por ende, una evaluación de la historia materializada a partir del lenguaje visual y corporal. Rescatadas desde una perspectiva histórica, representan la realidad del pasado, que adquiere significado por medio de ellas.

Guerra (2004) afirma que el adorno del cuerpo es una praxis presente en todos los grupos sociales y con una significativa función de código. Son signos que conciernen tanto a la identidad de un yo como a la relación de ese yo con su entorno cultural. El adorno es un conjunto de signos que inscriben en el cuerpo y en la mente los valores de un modelo social, más que una máscara decorativa.

Frente a la aparente simplicidad que presenta Bécquer la importancia de la joya para la mujer, la pieza narrativa La ajorca de oro en esta forma ulterior (entiéndase: la traducción española de Jesús Aguado a partir de una versión en inglés de Alain Daniélou de la obra de la tradición clásica tamil atribuida al príncipe Ilangô Adigal) admite algunos comentarios de índole epistemológica (que también se observan en la leyenda becqueriana). Cierto, hacer epistemología implica tratar bajo alguna perspectiva un determinado trabajo científico. Partimos de la convicción de que es cienciay no otra cosa, y ciencia experimental, toda manifestación artística. La única ciencia de lo humano que se ocupa sensu stricto del mundo personal. Ni la Antropología, ni la Filosofía, ni la Historia tratan de lo personal, sino de lo humano. El artista hace experimentación de lo personal diseccionando trozos de vida humana verosímil, puestos sobre el microscopio de la literatura, de la pintura, del cine. Lo personal es casuística de lo humano, mero fenómeno y, a la vez, su explicación. Por eso, es el arte ciencia plena y un tanto autosuficiente, solo por debajo de la Ética en jerarquía.

En La ajorca de oro de Adigal se da una profusión extraordinaria de elementos destinados a sublimar lo cotidiano, a arrebatar lo sensual hasta extremos estupefacientes, a sobreexigirle capacidad evocativa, representativa, al lector, para que plasme en su imaginación un mundo suntuoso y evasivo, en el que tiene lugar una historia. En esa historia suceden cosas -se trata de una narración-, pero es el mundo y las personas que en él se desenvuelven el verdadero asunto de la obra, un mundo (las cosas que hay en él, tal cual están en él) que no hace al caso su veracidad, ni siquiera su verosimilitud, sino que son mera potencia evocativa.

El sustantivo y el adjetivo tienen -y comparten entre sí- una gran aprehensibilidad, así como el destacable valor de las joyas (especialmente en el cuerpo de la mujer). El 
adjetivo, por su propia naturaleza adyacente, necesita de su sustantivo (de un sustantivo cualquiera, pero que hará suyo) y se diría que el sustantivo también tiende a necesitar de algún adjetivo que lo fije más rigurosamente en el orden interno (en la forma, en su acepción acuñada más arriba) del enunciado. Se alcanza una promiscuidad entre adjetivos y sustantivos sin más reglas que la lógica elemental de la inteligibilidad.

Al comienzo se ha hecho hincapié en la considerable distancia que nos separa de la lengua tamil en lo que respecta a este texto, por lo demás ambientado en épocas remotas de una civilización lejana. La lengua española, que procede del severo latín, rara vez se entrega a tan orgiástica profusión; es más parecida a la simplicidad de la exposición de la historia de Bécquer. Y La Ajorca de oro es casi una efusión. No hay sustantivo que se libre del avasallamiento de un adjetivo, cuando no de una hiperbólica comparación o de una fantasiosa analogía o de un epíteto afortunado. Es el modo a que está sometida esta narración, pero ese modo es consustancial a la forma. Como así el signo, el adorno femenino, que inscribe en el cuerpo y en la mente los valores de este exagerado modelo social, que no es decoración, es realidad. "Mujer de los valiosos brazaletes", a lo largo del texto no solo se repite el nombre de la joya (ajorca o brazalete), sino también el adjetivo (valioso), porque ciertos adjetivos eligen acertadamente a sus sustantivos obedeciendo a un orden en la configuración de las cosas dichas. Dicho más claramente, Kánnaki no es sino "la mujer de los valiosos brazaletes", es meramente eso. El epíteto empleado ubica al personaje en el imaginario desplegado en el texto con una cierta precisión, cobra y da sentido a la totalidad de estado de cosas que es ese mundo presentado en el texto.

En ambas obras, aunque de forma distinta, se pone de manifiesto cómo el amor es un universal cultural que conlleva una carga de significación. En este caso, el amor no parece ir más allá del cuerpo deseado en busca del alma, y es el adorno el que nos hace pensar que esto es así. El hombre y la mujer toman conciencia de su separatividad por este signo, más palpable en la circunstancia vital de Bécquer por motivos históricos, frente a la obra oriental, en la que el hombre todavía se adorna profusamente. Sin embargo, es la ajorca de oro en otra mujer la que conduce al hombre al engaño, al robo o al abandono (Kánnaki, la esposa, no lleva ajorca (p. 25). Sin embargo, la amante Mâdhavi se describe de esta forma antes de ofrecerse a Kôvalan: "cargó sobre sus tobillos pequeñas campanas, aros, cadenetas y ajorcas huecas”, (p. 35).

En todas las culturas surge el problema de la separatividad hombre y mujer, pero parece incapaz de alcanzar la compensación entre ambos seres, y es la joya (femenina) la que convierte el amor en una costura fácil de dividir, que fractura y daña especialmente a una de las partes sobre la que recae la supuesta responsabilidad de ser la que separa por ser la que se adorna. En la obra de Adigal se manifiesta en las siguientes referencias: la esposa Kánnaki afirma que "una mujer casada no debe adorar a nadie más que a su marido" y le confirma su fidelidad con la frase "todavía tienes los aros de oro de mis tobillos" (p. 55). En la leyenda de Bécquer, es el hombre el que responde a esta fidelidad con el robo de la misma. Las muchachas parecen tener los pies adornados con joyas como símbolo de fidelidad a los esposos. Asimismo, refiriéndonos a otra joya diferente, un collar de 
perlas, la doncella de la esposa Mâdhavi dice de ella que "se arrancó su espléndido collar de perlas" (p. 69) en señal de desgarro por el abandono de su marido. Y, al final de la obra, cuando la esposa va en busca de su esposo para vengar su muerte (fidelidad eterna), le cuentan cómo lo han ajusticiado acusado de haber robado la ajorca de la reina (p. IO4). Incluso en la resolución del conflicto, hay una tríada de gemas, perlas y ajorca que llevan al rey a comprender la verdad y su acto de injusticia tras haber matado al protagonista.

\section{Conclusiones}

Apartir de estas dos obras, hemos tratado de explicar la antigüedady la modernidad del tema de la representación de joyas, gemas y otros adornos corporales en la literatura. Partiendo de un análisis crítico de los dos textos, en el artículo se han intentado mostrar dos maneras diferentes en que los objetos diseñados para adornar el cuerpo intervienen en ambos textos literarios.

Como ya se ha indicado, el interés por la moda en la literatura (Gutiérrez García, 2005; Díaz Marcos, 2006; Pas, 20I4; Ruiz Cáceres, 20I8) es cada vez más significativo, porque la creciente multimodalidad de nuestros mecanismos de representación es en parte consecuencia de una serie de transformaciones que han afectado en el siglo XX a las formas de producción y reproducción de significado: en este caso en la literatura. Tras más de quinientos años en que el texto escrito constituyó una fuente predominante de conocimiento y de poder, las formas en estos representadas han empezado a proporcionar mayor poder a la imagen y a superponer, en algunos casos, imagen y texto escrito (Cope y Kalantzis, 20Iо).

La moda no es nueva en la literatura. Hemos puesto de manifiesto cómo en una obra del siglo II de nuestra era ya se había desarrollado un vínculo entre la literatura y la moda (la joyería), usada esta última para representar el grupo social y el género de los protagonistas entre otros. En estas obras, una misma joya demuestra que la moda no cambia tanto con el paso del tiempo, a pesar de los diferentes momentos históricos. En nuestros textos, las historias se estructuran en torno a una ajorca de oro, una de las cuales ha de ser robada por amor y otra conduce a la traición. Se ha tratado de explicar, desde una perspectiva de análisis semiótico-social, cuáles son las características del material multimodal en dichos textos, lo que exige que el lector deba ser capaz de "leer" multimodalmente las obras literarias.

El análisis de estos dos textos demuestra que hay al menos dos variantes en el discurso multimodal: una meramente semiótica (en la que objetos reales, iconos o gestos acompañan a la ejecución del discurso verbal, aportando elementos de naturaleza semántica) y una multimodalidad exclusivamente verbal o lingüística (en la que esos eventuales objetos, iconos o textos aparecen verbalizados en el discurso). Este sería el caso de las ajorcas de oro. En el texto de Adigal, las joyas, los adornos, la música, la profusión de objetos y animales solo aparecen mencionados. Son las meras palabras, cada 
vocablo, con su capacidad evocativa, a menudo sinestésica, las que aportan un contenido semiótico y, por extensión, metafórico al fondo del texto. Que prevalezca la ajorca es símbolo de la prevalencia de la virtud y la verdad (lealtad conyugal) más allá de la muerte. En el caso de Bécquer, la joya es tan solo un símbolo de objetualización que sirve para idealizar a la mujer de forma peligrosa porque se dibujan como mujeres joya o mujeres inalcanzables de historias en las que parecen dejar de ser de carne y hueso, deseadas por el hombre. 


\section{Bibliografía}

-Adigal, P. I. (20O7). La ajorca de oro (Shilappadikaram), Traducción de Jesús Aguado, Colección El Barquero.

- Bécquer, G. A. (2019). Leyendas, Ed. Pascual Izquierdo. Colección Letras Hispánicas, Ediciones Cátedra, 33. ${ }^{a}$ edición, 195-2O4.

- Cárcamo Morales, B. (20I8). “El análisis del discurso multimodal: una comparación de propuestas metodológicas". Forma y Función, 3I(2): I45-I74.

- Cope, B., y Kalantzis, M. (20Iо). "Gramática de la multimodalidad". Boletín de la Asociación Andaluza de Bibliotecarios, 25, 98-99: 93-I54.

- Díaz Marcos, A.M. (2006). La edad de seda: representaciones de la moda en la literatura española (I728-1926), Servicio de publicaciones, Universidad de Cádiz.

- Guerra, L. (2004). "Cuerpo de mujer y rituales del adorno en "Ifigenia" de Teresa de la Parra”, Letras Femeninas, Número especial Cuerpo/género/texto: el imaginario corporal en la literatura femenina hispánica, 30, I: I29-I40.

- Gutiérrez García, M. A. (2005). "Literatura y moda: La indumentaria femenina a través de la novela española del siglo XIX”. Tonos. Revista Electrónica de Estudios Filológicos, 9.

- Halliday, M. (2004). An Introduction to Functional Grammar. (3rd ed, revised by C. M. I. Matthiessen). London: Arnold.

- Hug, T. (2013). "Competencia mediática y alfabetización visual. Hacia consideraciones más allá de las alfabetizaciones”, Razón y palabra, 82.

- Jewitt, C. (2009). “An Introduction to Multimodality”. En Jewitt, C. (Ed.), The Routledge Handbook of Multimodal Analysis. London and New York: Routledge.

- Kress, G. y Van Leeuwen, T. (2006). Reading Images: The Grammar of Visual Design. London/ New York: Routledge.

- Mangui, D. (20I3). "Géneros en la enseñanza escolar: Configuraciones de significado en clases de historia y biología desde una perspectiva multimodal”. Revista Signos. Estudios de Lingüistica, 46(82): $236-257$.

- O’Halloran, K. y Lim, V. (2OI4). "Systemic Functional Multimodal Discourse Analysis", En S. Norris and C. Maier (eds), Texts, Images and Interactions: A Reader in Multimodality. Berlin: Mouton de Gruyter, I37-I54. 
- O’Toole, M. (2010). The Language of Displayed Art (2nd ed). London and New York: Routledge.

- Pas, H. (20I4). "Víctor Goldgel, Cuando lo nuevo conquistó América. Prensa, moda y literatura en el siglo XIX”. Orbis Tertius, I9(20), I67-I70.

- Parodi, G. (2OIO). "Multisemiosis y lingüística de corpus: Artefactos (multi) semióticos en los textos de seis disciplinas en el Corpus pucv-20іо”. RLA, 48(2), 33-70.

- Prensky, M. (200I), "Digital Natives, Digital Immigrants Part I”, On the Horizon, 9: I-6.

- Rivera Garretas, M. M. (2006). "El culto a la belleza”, Lectora: revista de dones itextualitat, I2: I25-I28.

- Ruiz Cáceres, R.M. (20I8). Literatura y moda en la España finisecular del siglo XVIII y centuria del XIX. Tesis doctoral inédita. Universidad de Alicante.

- Zabalgoitia Herrere, M. (2OII). "Szurmuk, Mónica y Mckee, Robert (coords.), Diccionario de estudios culturales latinoamericanos, México, D.F.: Siglo XXI, 20o9”, Mitologías hoy: Revista de pensamiento, crítica y estudios literarios latinoamericanos, I: І26-I29. 